Article

\title{
Studies on Curing Kinetics and Tensile Properties of Silica-Filled Phenolic Amine/Epoxy Resin Nanocomposite
}

\author{
Ting Zheng ${ }^{1,2,+} \oplus$, Xiaodong Wang ${ }^{1,+, *} \mathbb{C}$, Chunrui Lu ${ }^{2,+} \oplus$, Xiaohong Zhang ${ }^{1}$, Yi Ji ${ }^{1}$, \\ Chengying Bai ${ }^{1} \mathbb{C}$, Yiwen Chen ${ }^{1}$ and Yingjie Qiao ${ }^{1}$ \\ 1 School of Material Science and Chemical Engineering, Harbin Engineering University, Harbin 150001, China; \\ zthappy1127@gmail.com (T.Z.); zhangxiaohong@hrbeu.edu.cn (X.Z.); memory330@126.com (Y.J.); \\ chengyingbai@163.com (C.B.); ztqiuqiu@126.com (Y.C.); qiaoyingjie99@163.com (Y.Q.) \\ 2 School of Materials Science and Engineering, Harbin Institute of Technology, Harbin 150001, China; \\ luchunrui06@126.com \\ * Correspondence: wangxiaodong@hrbeu.edu.cn; Tel.: +86-451-8256-8337 \\ + These authors contributed equally to this work.
}

Received: 6 March 2019; Accepted: 12 April 2019; Published: 15 April 2019

\begin{abstract}
In this study, the curing kinetics of the phenolic amine/epoxy resin system were investigated by nonisothermal differential scanning calorimetry (DSC). The model-free isoconversional method of Ozawa-Flynn-Wall reveals a dependence of $E_{\alpha}$ (activation energy) on conversion ( $\alpha$ ), which interprets the autocatalytic curing reaction mechanism of the phenolic amine/epoxy resin system. Studies on the effects of nano- $\mathrm{SiO}_{2}$ particles on the tensile properties and tensile fracture face morphology of nanocomposites show that the uniform dispersion of $\mathrm{SiO}_{2}$ nanoparticles plays an important role in promoting the tensile performance of nanocomposites. Additionally, increases of $184.1 \%$ and $217.2 \%$ were achieved by adding $1.5 \%$ weight parts of nano- $\mathrm{SiO}_{2}$ in composites for the tensile strength and tensile modulus, respectively.
\end{abstract}

Keywords: cure kinetics; tensile strength; epoxy resin; nanocomposite

\section{Introduction}

As an important transportation equipment for offshore oil and gas exploitation, the safety of submarine oil-gas pipelines is related to the normal operation of offshore oil and gas exploitation system. Once the failure of submarine oil-gas pipelines occurs, it will not only cause the exploitation shutdown and the pollution of environment by crude oil, but also affect the normal production and life of an oil-gas supplier [1-3]. However, the traditional techniques widely used in repairing onshore pipelines are difficult to implement under water due to the complex undersea environment, long construction period, low repair speed and complex operational procedures [4-6]. Thus, it is urgent to develop a rapid and effective underwater repair technique to reduce loss and damage once oil-gas pipeline leaks.

Epoxy resins are very versatile materials with a wide range of applications based on their excellent chemical/corrosion resistance and mechanical properties [7]. For the past few decades, epoxy resins have been successfully applied in emergency repair and sealing of oil-gas pipelines due to the advantages of no welding, no production stopping, high construction safety, and low cost $[8,9]$. Epoxy resins' composition, comprising phenolic amine curing agents prepared by the Mannich reaction, shows good, obtainable surface properties, in particular for coating, adhesively bonding and enhancing metallic and mineral substrates as an adhesive and sealant, and for producing moldings and sheet-like structures [10]. More importantly, this phenolic amine/epoxy resin system 
can be cured in a water-containing environment, thus it is considered to be a suitable material for underwater sealing and curing applications. It is well known that the physical properties of cured epoxy resins depend on the structure of their crosslinking network, curing extent, and the time and temperature of the curing reaction [11,12]. Such curing kinetics parameters related to network formation could provide substantial information concerning the final structure and properties of the epoxy resin network, and also the processability of epoxy resin. Therefore, the curing kinetics analysis of epoxy resin is essential to understand the structure-property-processing relationship for the preparation of high-performance composites [12]. However, there are few reports on the curing kinetics analysis of the phenolic amine/epoxy resin system until now.

In this work, dynamic differential scanning calorimetry (DSC) was used to study the curing kinetics of the phenolic amine/epoxy resin system. Detailed curing kinetics analysis was performed using the model-free isoconversional method of Ozawa-Flynn-Wall. Moreover, there are many unsaturated residual bonds and hydroxyl groups in different bonding states on the surface of nano-SiO 2 particles, which is beneficial in improving interfacial bonding with the epoxy resin matrix in physical or chemical ways [13-17]. Therefore, nano-SiO 2 particles were also used to further improve the mechanical properties of phenolic amine/epoxy resin composites. The influence of nano-SiO $\mathrm{S}_{2}$ article addition to epoxy resin on the tensile properties and fracture face morphology of the phenolic amine/epoxy resin system was also investigated. Based on the results, silica-filled phenolic amine/epoxy resin nanocomposites with good mechanical properties are a promising water-containing curing material for underwater speedy repair and sealing applications.

\section{Materials and Methods}

\subsection{Materials}

A diglycidyl ether of bisphenol A type epoxy resin (DGEBA) provided by Nantong Xingchen Synthetic Material Co., Ltd. (Nantong, China) with an epoxy value of 0.51 was used in this study. Phenolic amine 810 provided by Changsha Chemical Industry Research Institute (Changsha, China) was applied to the hardener, and the neopentyl glycol diglycidyl ether (NGDE) supplied by Anhui Xinyuan Chemical Co., Ltd. (Huangshan, China) was added into the epoxy resin as a reactive diluent. Nano-SiO 2 with a mean diameter of $12 \mathrm{~nm}$ was purchased from Evonik Degussa (Shanghai, China) and had an apparent density of $30 \mathrm{~kg} / \mathrm{m}^{3}$ and a surface area of $200 \pm 25 \mathrm{~m}^{2} / \mathrm{g}$. The chemicals were used as received without further purification. The chemical structures of all materials used in this work are shown in Figure 1.

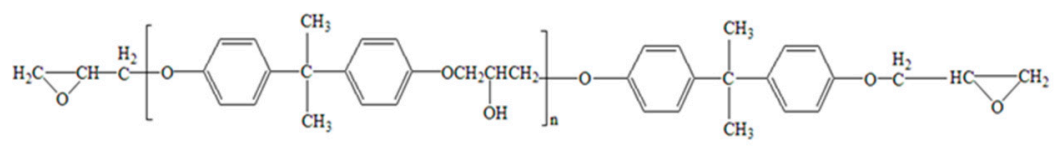

(a)

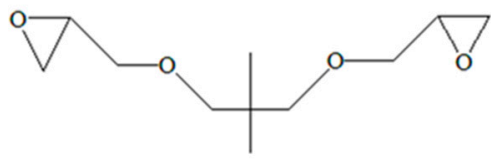

(b)

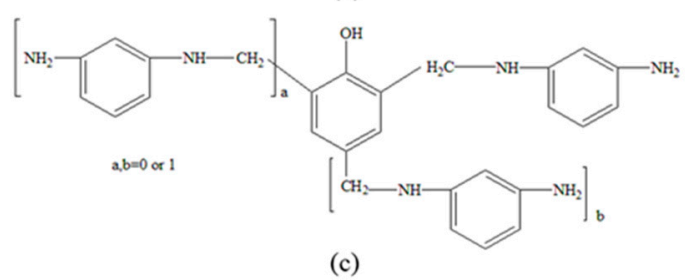

(c)

Figure 1. The structures of chemicals: (a) Diglycidyl ether of bisphenol A type epoxy resin (DGEBA), (b) neopentyl glycol diglycidyl ether (NGDE), and (c) phenolic amine 810. 


\subsection{Dynamic DSC Analysis}

Studies on the curing kinetics of the phenolic amine/epoxy resin system were carried out using a differential scanning calorimeter (DSC, 204 F1, NETZSCH, Selb, Germany). DGEBA, NGDE and phenolic amine 810 were mixed at room temperature based on their determined stoichiometric ratio. Samples of 5-10 mg were sealed in aluminum pans in respect to dynamic DSC scans, and heated up to $200{ }^{\circ} \mathrm{C}$ from a room temperature of $20{ }^{\circ} \mathrm{C}$ at a series of heating rates of $5,10,15,20$ and $25^{\circ} \mathrm{C} / \mathrm{min}$, respectively.

\subsection{Preparation of Nanocomposites}

Nano- $\mathrm{SiO}_{2}$ particles were placed into a vacuum oven and heated at $100{ }^{\circ} \mathrm{C}$ for $2 \mathrm{~h}$ until the mass remained stable. The level of phenolic amine curing agent incorporation was based on the epoxy value of DGEBA according to the empirical formula of $q=(1.3 \sim 1.4) \times k \times 43$, where $q$ and $k$ are the amount of addition of phenolic amine curing agent per hundred of epoxy resin and the epoxy value, respectively [18]. According to this empirical formula, approximately $30 \mathrm{~g}$ of phenolic amine 810 was required for $100 \mathrm{~g}$ DGEBA. Epoxy-based reactive diluent NGDE can participate, together with DGEBA and phenolic amine 810, in polymerization and crosslinking reactions; therefore, $5 \mathrm{~g}$ more of NGDE was used in the phenolic amine/epoxy resin system.

In this paper, different formulations of DGEBA with phenolic amine 810 and NGDE were developed by varying the weight parts of $\mathrm{SiO}_{2}$ nanoparticles. The formulas employed in this study are listed in Table 1. The resultant materials were completely mixed by a mechanical stirrer and degassed with a vacuum pump to eliminate air bubbles. The bubble-free mixtures were then poured into preheated steel molds in an oven following curing at $40{ }^{\circ} \mathrm{C}$ for $3 \mathrm{~h}$. Besides this, tensile test specimens were developed according to ASTM D638 tensile sample specification.

Table 1. Weight parts of each materials in phenolic amine/epoxy resin system for tensile performance testing.

\begin{tabular}{ccccc}
\hline \multirow{2}{*}{ Samples } & \multicolumn{4}{c}{ Component and Content } \\
\cline { 2 - 5 } & DGEBA & $\mathbf{8 1 0}$ & NGDE & Nano-SiO $_{2}$ \\
\hline 1 & 100 & 35 & 30 & 0 \\
2 & 100 & 35 & 30 & 1.0 \\
3 & 100 & 35 & 30 & 1.5 \\
4 & 100 & 35 & 30 & 2.0 \\
5 & 100 & 35 & 30 & 2.5 \\
\hline
\end{tabular}

\subsection{Tensile Test of Nanocomposites}

A tensile test of all samples was carried out by a tensile tester (Instron 1196, Instron Corporation, Norwood, MA, USA) with a crosshead speed of $10 \mathrm{~mm} / \mathrm{min}$ at room temperature. The tensile strength and tensile modulus of specimens were determined at the yield point and $0.5 \%$ strain, respectively. Five replicates were taken for each of the properties measured and the results given are the averages of five experimental values.

\subsection{Scanning Electron Microscopy}

The fracture surface morphology analysis of nanocomposites was performed using a scanning electron microscope (Phenom Pure, Phenom Scientific Instrument (Shanghai) Co. Ltd., Shanghai, China) at a $5 \mathrm{kV}$ accelerating voltage. All specimen surfaces for SEM observation were coated with a thin gold film to protect fracture surfaces from beam damage and to prevent charge build-up. 


\section{Results}

\subsection{DSC Cure Characterization}

The typical DSC curves of DGEBA cured with 35 weight parts of 810 and 30 weight parts of NGDE displaying heat flow $d H / d t$ against temperature $T$ are shown in Figure 2 . The information about the nature of the curing reaction, such as onset temperature $T_{\mathrm{i}}$, peak temperature $T_{\mathrm{p}}$, terminal temperature $T_{\mathrm{f}}$ and total exothermic reaction heat, can also be inferred from these curves, the results are listed in Table 2. It can be observed that, at any heating rate, there is a single broad peak. With an increase in heating rate, the exothermic peak temperature shifted to a higher value, because at a slow heating rate, the system took more time to get cured, and vice versa. In order to eliminate the influence of heating rate on curing system, $T-\beta$ extrapolation method was used to calculate the gel point temperature (the initial temperature) $T_{\text {gel }}$ and curing temperature (peak temperature) $T_{\mathrm{pc}}$ and post-curing temperature (termination temperature) $T_{\mathrm{fc}}$ at $\beta=0$ [19]. $T_{\mathrm{i}}, T_{\mathrm{p}}$ and $T_{\mathrm{f}}$ were plotted against the heating rate $\beta$, and the curves were extrapolated to $\beta=0$. Finally, the extrapolated results of $T_{\mathrm{i}}, T_{\mathrm{p}}$ and $T_{\mathrm{f}}$ of phenolic amine/epoxy resin system were $37.12,72.39$ and $106.35^{\circ} \mathrm{C}$, respectively. These results provide reference for the curing process temperature of phenolic amine/epoxy resin system.

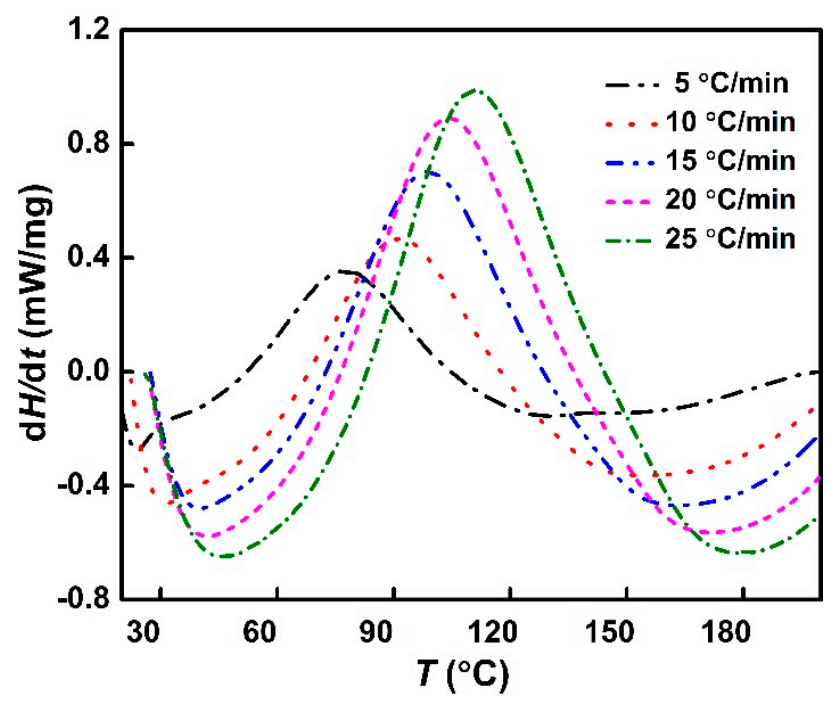

Figure 2. Differential scanning calorimetry (DSC) curves of the phenolic amine/epoxy resin system.

Table 2. Data from the analysis of DSC measurements at different heating rates.

\begin{tabular}{ccccc}
\hline Heating Rate $\left({ }^{\circ} \mathbf{C} / \mathbf{m i n}\right)$ & $\boldsymbol{T}_{\mathbf{i}} /{ }^{\circ} \mathbf{C}$ & $\boldsymbol{T}_{\mathbf{p}} /{ }^{\circ} \mathbf{C}$ & $\boldsymbol{T}_{\mathbf{f}} /{ }^{\circ} \mathbf{C}$ & $\Delta \boldsymbol{H}_{\text {total }}(\mathbf{J} / \mathbf{g})$ \\
\hline 5 & 40.73 & 77.41 & 112.6 & 247.1 \\
10 & 52.74 & 91.13 & 134.7 & 222.5 \\
15 & 58.16 & 98.50 & 146.0 & 184.6 \\
20 & 62.30 & 103.7 & 153.2 & 177.9 \\
25 & 68.08 & 111.1 & 162.4 & 162.5 \\
\hline
\end{tabular}

\subsection{Curing Kinetics Analysis}

In nonisothermal DSC measurement, it is basically assumed that the measured heat flow, $d H / d t$, is proportional to the reaction rate, $d \alpha / d t$ [20]. For an unknown reaction mechanism, the reaction rate at a given time is considered to be the function of cure degree $\alpha$ [21], hence

$$
d \alpha / d t=k f(\alpha)
$$


where $k$ is the reaction rate constant and $f(\alpha)$ is a functional form of $\alpha$ depending on the reaction mechanism. $k$ is assumed to be the Arrhenius form, so

$$
k=A \exp (-E / R T)
$$

where $A$ is the pre-exponential factor, $R$ is the universal gas constant, $E$ is the value of activation energy and $T$ is the absolute temperature. Equation (1) can be utilized to perform nonisothermal DSC experiments at different heating rates, $\beta=d T / d t$. By processing DSC curve data at different heating rates, it was easy to obtain the kinetic parameters above.

Peak temperature data for different heating rates from nonisothermal thermograms of each formulation were used to calculate the activation energy of the cure reaction, and the Kissinger and Ozawa methods were used for this calculation. According to the following formula,

$$
\ln \left(\beta / T_{\mathrm{p}}^{2}\right)=A \exp (-E / R T)
$$

The Kissinger method [22] is a linear plot of $\ln \left(\beta / T_{\mathrm{p}}^{2}\right)$ versus $1 / T_{\mathrm{p}}$. The values of activation energy $E$ and pre-exponential factor $A$ can be obtained by calculating the slope of linear fit and the intercept, respectively.

The Ozawa method [23] relates the logarithm of heating rate and the inverse of exothermic peak temperature, that is, $\ln (\beta)$ versus $1 / T_{\mathrm{p}}$. Therefore, the activation energy can be determined from the resultant slope:

$$
\begin{gathered}
\ln (\beta)=\ln (A E / R)-\ln F(\alpha)-5.331-1.052\left(E / R T_{\mathrm{p}}\right) \\
F(\alpha)=\int_{0}^{a} \frac{d \alpha}{f(\alpha)}
\end{gathered}
$$

where $F(\alpha)$ is a constant function [24].

Figure $3 \mathrm{a}, \mathrm{b}$ gives linear fit plots of the methods of Kissinger and Ozawa, respectively. Activation energies obtained from Kissinger and Ozawa methods are $51.92 \mathrm{~kJ} / \mathrm{mol}$ and $48.64 \mathrm{~kJ} / \mathrm{mol}$, respectively. The pre-exponential factor, $A$, can be determined by calculating the slope of the linear fit and the y-intercept through Figure 3a.
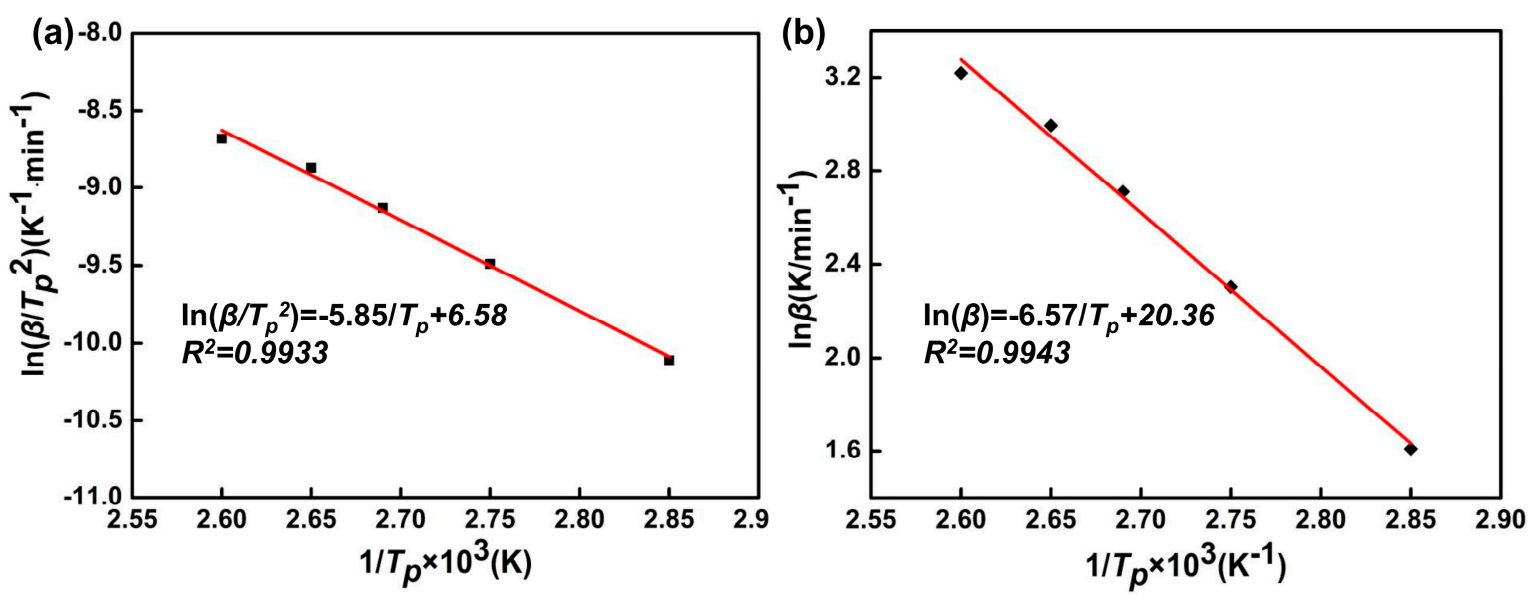

Figure 3. E determination of the phenolic amine/epoxy resin system by (a) the Kissinger method and (b) the Ozawa method. 
In addition, the simplest model used to describe the cure behavior of thermosets is the n-order curing reaction kinetic model generally (Equation (6)). The reaction order, $n$, of curing phenolic amine/epoxy resin system can be calculated from the Crane equation [25]:

$$
\begin{gathered}
f(\alpha)=(1-\alpha)^{\mathrm{n}} \\
\frac{d \ln \beta}{d\left(\frac{1}{T_{p}}\right)}=-\left(\frac{E}{n R}+2 T_{p}\right)
\end{gathered}
$$

The reaction order, $n$, could be calculated by the slope of Figure $3 \mathrm{~b}$ and the Crane equation. The average activation energy of Kissinger and Ozawa model methods and kinetic parameters are displayed in Table 3.

\begin{tabular}{|c|c|c|}
\hline$E\left(\mathrm{~kJ} \cdot \mathrm{mol}^{-1}\right)$ & $\mathrm{n}$ & $A\left(\min ^{-1}\right)$ \\
\hline 50.28 & 0.94 & $4.22 \times 10^{6}$ \\
\hline
\end{tabular}

Table 3. Kinetic parameters determined by fitting nonisothermal DSC measurements.

\subsection{The Numerical Model of Curing Degree and Time}

The actual curing reaction process can be predicted by using the kinetic parameters obtained above. Firstly, the equation of curing reaction rate cab be determined from Equations (1), (2) and (6):

$$
\frac{\mathrm{d} \alpha}{\mathrm{dt}}=\mathrm{A} \cdot \exp \left(-\frac{E}{\mathrm{RT}}\right)(1-\alpha)^{n}
$$

Introducing kinetic parameters in Equation (8), n-order reaction models of phenolic amine/epoxy resin composites can be defined as:

$$
\frac{\mathrm{d} \alpha}{\mathrm{dt}}=4.22 \times 10^{6} \cdot \exp \left(-\frac{6.05 \times 10^{3}}{\mathrm{~T}}\right)(1-\alpha)^{0.94}
$$

Curing degree (or conversion) presents the degree of macro-reaction curing reaction and determines the curing performances of phenolic amine/epoxy resin composites. The dynamic model of curing degree of phenolic amine/epoxy resin composite was obtained by integrating the n-order kinetic model equation obtained above:

$$
\alpha=1-\left[\mathrm{A} \cdot \exp \left(-\frac{E}{R T}\right)(n-1) t+1\right]^{\frac{1}{1-n}}
$$

The curing reaction kinetics model of phenolic amine/epoxy resin composites can be established by substituting the parameters of $E, A$ and $n$ into integral Equation (11):

$$
\alpha=1-\left[1-2.53 \times 10^{5} \cdot \exp \left(-\frac{6.05 \times 10^{3}}{T}\right) t\right]^{16.67}
$$

Formula (11) reflects the relationship of curing degree $\alpha$, curing temperature $T$ and curing time $t$. Through this formula, the relationship between $\alpha$ and $t$ of phenolic amine/epoxy resin composites at different temperatures can be obtained. Therefore, the actual curing reaction process can be predicted. The curves of curing time and curing degree of phenolic amine/epoxy resin composites at different temperatures are presented in Figure 4. It shows that extending reaction time and increasing reaction temperature are two effective methods to achieve the same curing degree. In order to shorten the curing time, $40^{\circ} \mathrm{C}$ and $3 \mathrm{~h}$ were selected as curing parameters in this paper. In this condition, phenolic amine/epoxy resin composites are cured almost completely. 


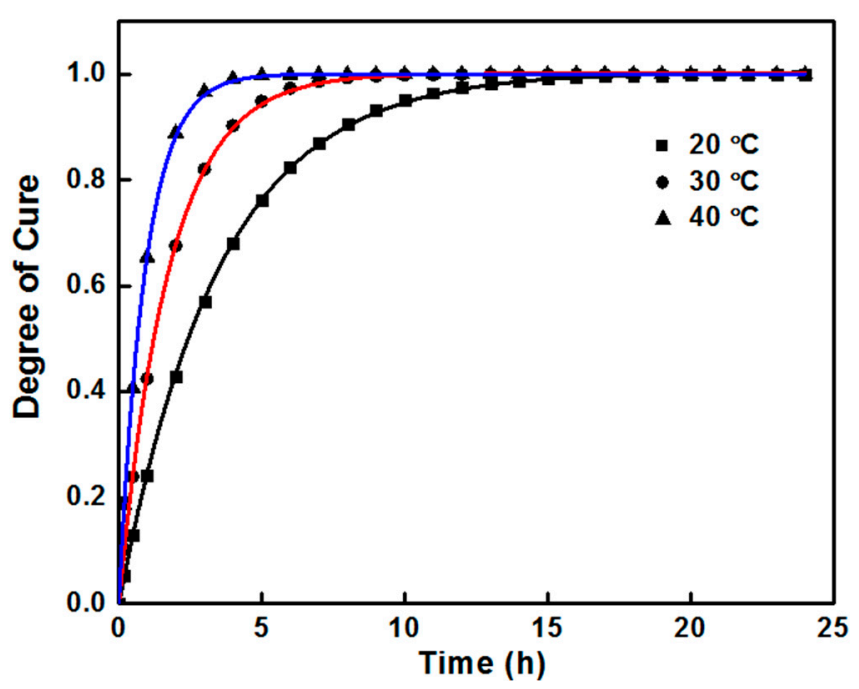

Figure 4. The degree of cure as a function of time at different cure temperature.

\subsection{Model-Free Isoconversional of Ozawa-Flynn-Wall}

Epoxy resin curing is a complicated process due to the presence of gelation and vitrification, and therefore it is considered to be a multi-step reaction [26]. Isoconversional methods, which assume that the conversion is constant at the curing reaction DSC peak and independent of the several heating rates used, have been previously applied to the curing kinetics analysis of many other thermosetting systems and require no knowledge of the reaction model [27]. The above methods of Kissinger and Ozawa have the limitation of producing a single value of $E$ for the whole process, which is a sign of a single-step process [28]. Model-free isoconversional methods can help to observe variations in apparent activation energy at different degrees of curing. The isoconversional method, more importantly, is able to explain the curing reaction mechanism by observing the change of apparent activation energy with conversion.

A more complete determination of $E$ at any selected conversion can be received by adopting the popular isoconversional method of Ozawa-Flynn-Wall which relates conversion-dependent apparent activation energy, heating rate, and isoconversion temperature [29,30]. The basic equation of the Ozawa-Flynn-Wall method is

$$
\begin{gathered}
\ln (\beta)=\ln \left(A E_{\alpha} / R\right)-\ln G(\alpha)-5.331-1.052\left(E_{\alpha} / R T_{\alpha}\right) \\
G(\alpha)=\int_{0}^{\alpha} \frac{d \alpha}{f(\alpha)}
\end{gathered}
$$

where $E_{\alpha}$ is the value of apparent activation energy, $T_{\alpha}$ is the isoconversion temperature and $G(\alpha)$ is the integral conversion function.

A transformation was performed to convert nonisothermal DSC scans into fractional conversion versus isoconversional temperatures at different heating rates. A representative of this transformation is shown in Figure 5 for the phenolic amine/epoxy resin system.

The curing reaction rate, $d \alpha / d t=d H / d t / \Delta H_{\text {total }}$, versus the conversion plot is also shown in Figure 6 . The value of $d \alpha / d t$ increased to the maximum and then decreased to 0 with the increasing of $\alpha$. Although increasing the heating rate promotes the reaction process, the maximum $d \alpha / d t$ values of reaction rate at a corresponding conversion rate is not basically changed. All $\alpha$ are in the range of $0.3-0.5$, which is a character of an autocatalytic reaction [28]. 


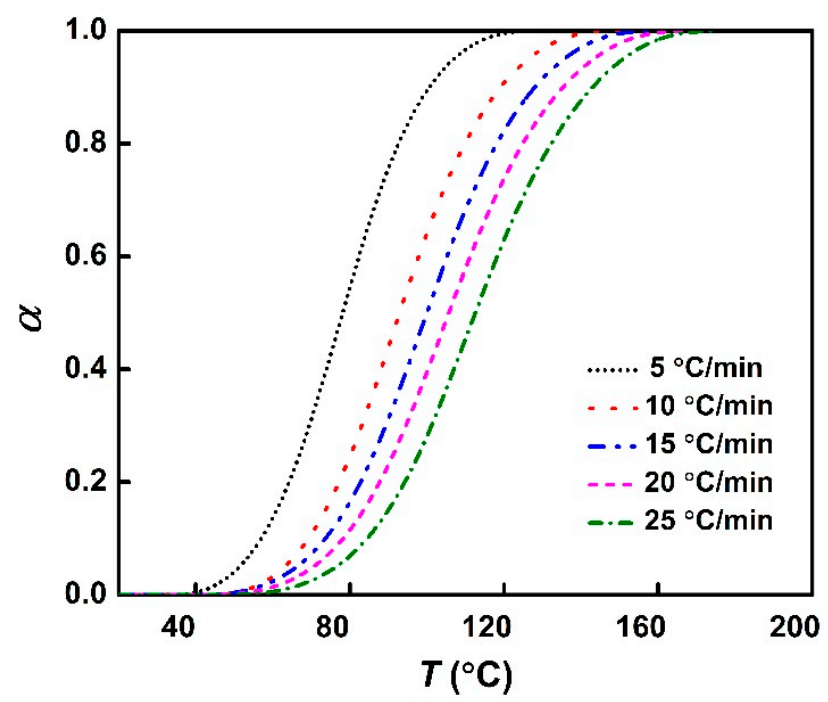

Figure 5. Conversion vs. temperature at different heating rates for the phenolic amine/epoxy resin system.

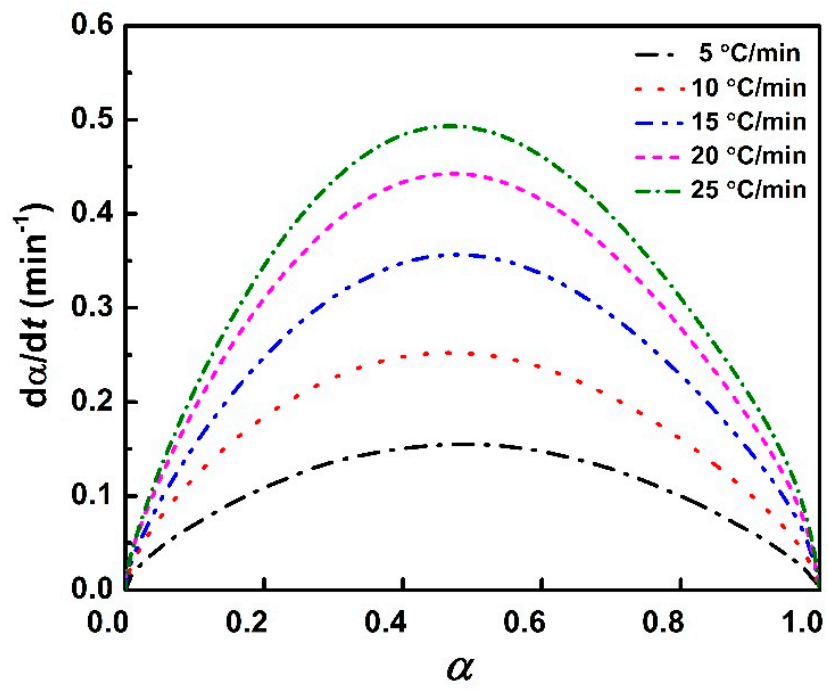

Figure 6. Reaction rate vs. conversion plot at different heating rates.

In order to understand apparent activation energy-conversion dependence, a plot of $\ln \beta$ as a function of $1 / T_{\alpha}$ obtained from DSC thermograms using various heating rates yields straight lines whose slope value is used to calculate the apparent activation energy (Figure 7a). Then, the activation energies calculated were plotted as shown in Figure $7 \mathrm{~b}$ as a function of conversion. It is seen that $\mathrm{E}_{\alpha}$ is highest at the beginning of curing, and then decreases with conversion throughout the entire curing process. The process of the curing reaction is autocatalytic because phenolic amine is an efficient hydrogen-bond donor molecule that promotes the ring opening of the epoxy group in the same way as the hydroxyl group of epoxy resin, leading to an auto-accelerating effect on the curing reaction and a decrease in apparent activation energy [31,32]. In the initial stages of reaction, the generated hydroxyl groups are less and the catalytic effect is not obvious, thus the reaction activation energy is higher. As the reaction continues, the generated hydroxyl groups increase to promote the catalytic reaction effectively, the activation energy will be decreased. In addition, the temperature of the curing system increases and viscosity is reduced during the process of the curing reaction. These also accelerate the diffusion rate and reduce the activation energy [33]. 

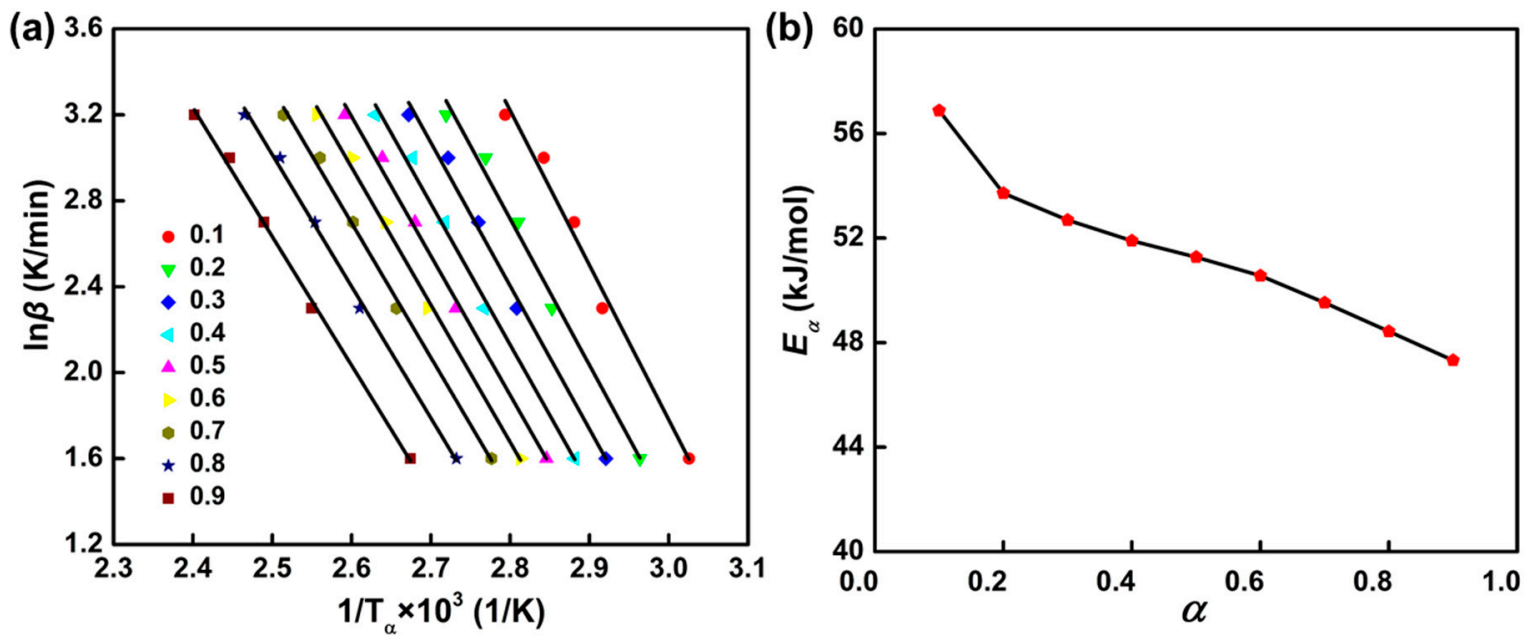

Figure 7. (a) Ozawa-Flynn-Wall method to determine apparent activation energy at different conversion rates. (b) Dependence of apparent activation energy on the conversion of the phenolic amine/epoxy resin system.

However, it is noteworthy that the $E_{\alpha}$ varies in a narrower range (about $10 \mathrm{~kJ} / \mathrm{mol}$ ) with respect to $\alpha$ compared to the range reported for other epoxy-amine systems [34]. Values around $50 \mathrm{~kJ} / \mathrm{mol}$ were obtained, which are in good agreement with Kissinger and Ozawa model-fitting kinetics values and literature data for the autocatalytic reaction of an epoxy-amine system [35]. The rate-determining steps for autocatalytic reactions correspond to the formation of a trimolecular transition state amine-epoxy-hydroxyl, maybe as shown in Figure 8, where HX represents a hydrogen-bond donor.

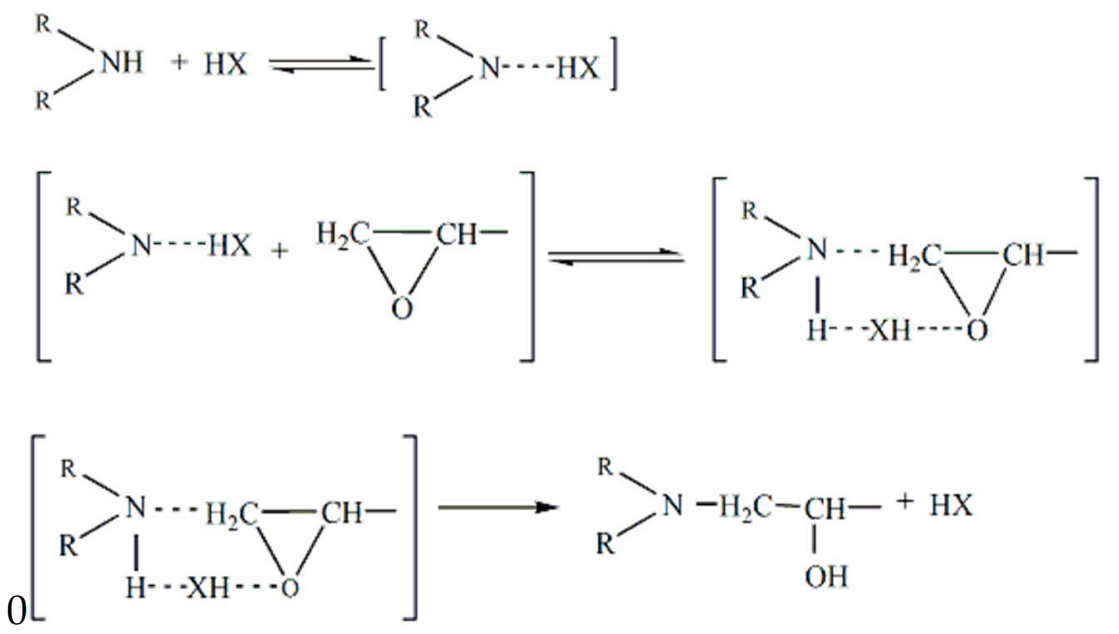

Figure 8. Schematic illustration of a trimolecular transition state amine-epoxy-hydroxyl.

\section{5. $\mathrm{SiO}_{2} /$ Epoxy Nanocomposites}

The tensile strength obtained for $\mathrm{SiO}_{2}$ /epoxy nanocomposites with different weight parts of nano- $\mathrm{SiO}_{2}$ particles in nanomaterials system is plotted in Figure 9. It shows that the tensile strength of nanocomposites increases with the addition of $\mathrm{SiO}_{2}$ nanoparticles up to 1.5 weight parts, where the value of tensile strength reaches its maximum and then decreases with further additions. The tensile strength of nanocomposites with 1.5 weight parts of nano- $\mathrm{SiO}_{2}$ particles increased remarkably up to 36.38 MPa in comparison with the pure epoxy resin with a tensile strength of $12.60 \mathrm{MPa}$. 

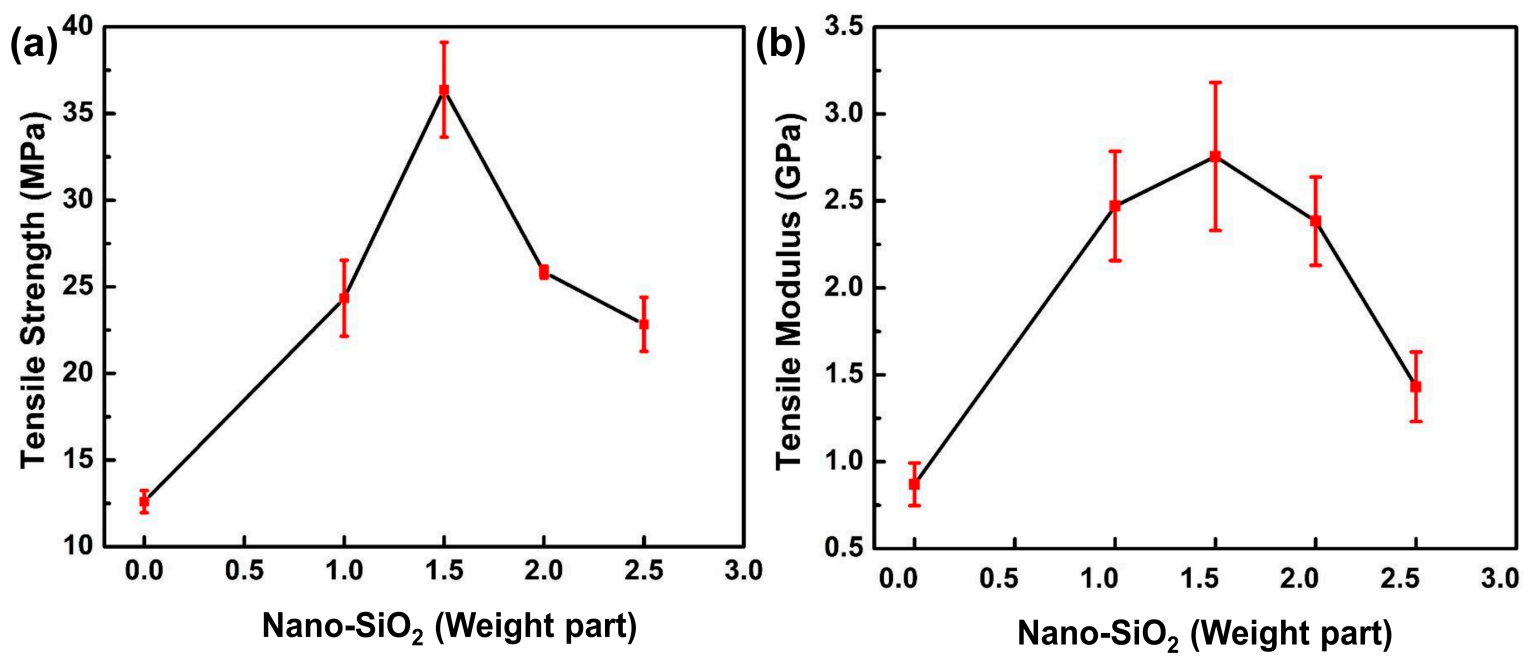

Figure 9. (a) Tensile strength and (b) tensile modulus vs. nano- $\mathrm{SiO}_{2}$ content for nanocomposites.

A similar tendency for the tested parameters in terms of the variation of nano- $\mathrm{SiO}_{2}$ particles content was observed for the tensile modulus of nanocomposites, as shown in Figure $9 \mathrm{~b}$. The tensile modulus was enhanced significantly with 1.5 weight parts of $\mathrm{SiO}_{2}$ nanoparticles in nanomaterials system, and the value of the tensile modulus increased by $217.2 \%$.

The dispersion ability of $\mathrm{SiO}_{2}$ nanoparticles in epoxy resin is believed to be responsible for the increase-then-decrease phenomenon in terms of its tensile properties [36]. $\mathrm{Nano}-\mathrm{SiO}_{2}$ particles are shown to have a strong agglomerating trend, so that the homogeneous dispersion of $\mathrm{SiO}_{2}$ nanoparticles has been considered to be a difficult and important process [37]. A good dispersion, however, can be achieved by surface modification and appropriate processing conditions [38,39]. In this work, nano- $\mathrm{SiO}_{2}$ particles were sufficiently premixed with NGDE and placed for more than $8 \mathrm{~h}$ at room temperature. Of course, a reasonably good distribution of $\mathrm{SiO}_{2}$ nanoparticles can be achieved at a low content.

Figure 10 exhibits typical SEM micrographs of tensile fracture surfaces of nanocomposites containing different weight parts of nano- $\mathrm{SiO}_{2}$ particles. Noticeably, an amount of wrinkles (Figure $10 \mathrm{~b}, \mathrm{c}$ ) appear on the fracture surfaces of nanocomposites with 1.0 and 1.5 weight parts of nano- $\mathrm{SiO}_{2}$ particles in contrast with the relatively smooth one (Figure 10a), indicating that massive new surfaces were created under tensile loading. This should maximize the interaction between $\mathrm{SiO}_{2}$ nanoparticles and epoxy resin, and much more energy can be dissipated through these new surfaces, leading to significant improvement of the tensile properties of nanocomposites with 1.0 and 1.5 weight parts nano- $\mathrm{SiO}_{2}$ particles (Figure 9).

Further additions of $\mathrm{SiO}_{2}$ nanoparticles generally make uniform dispersion difficult, resulting in a weak-bonding interface between the filler and matrix. We can observe that small aggregates begin to appear on the fracture surfaces of nanocomposites with 2.0 weight parts nano- $\mathrm{SiO}_{2}$ particles as Figure $10 \mathrm{~d}$ and its enlarged SEM picture displayed. The nanocomposite with 2.5 weight parts nano- $\mathrm{SiO}_{2}$ particles shows even more clusters (as indicated by the red circles in Figure 10e). This may be the main and a reasonable interpretation of the reduction on the tensile properties of nanocomposites with 2.0 and/or 2.5 weight parts nano- $\mathrm{SiO}_{2}$ particles. 

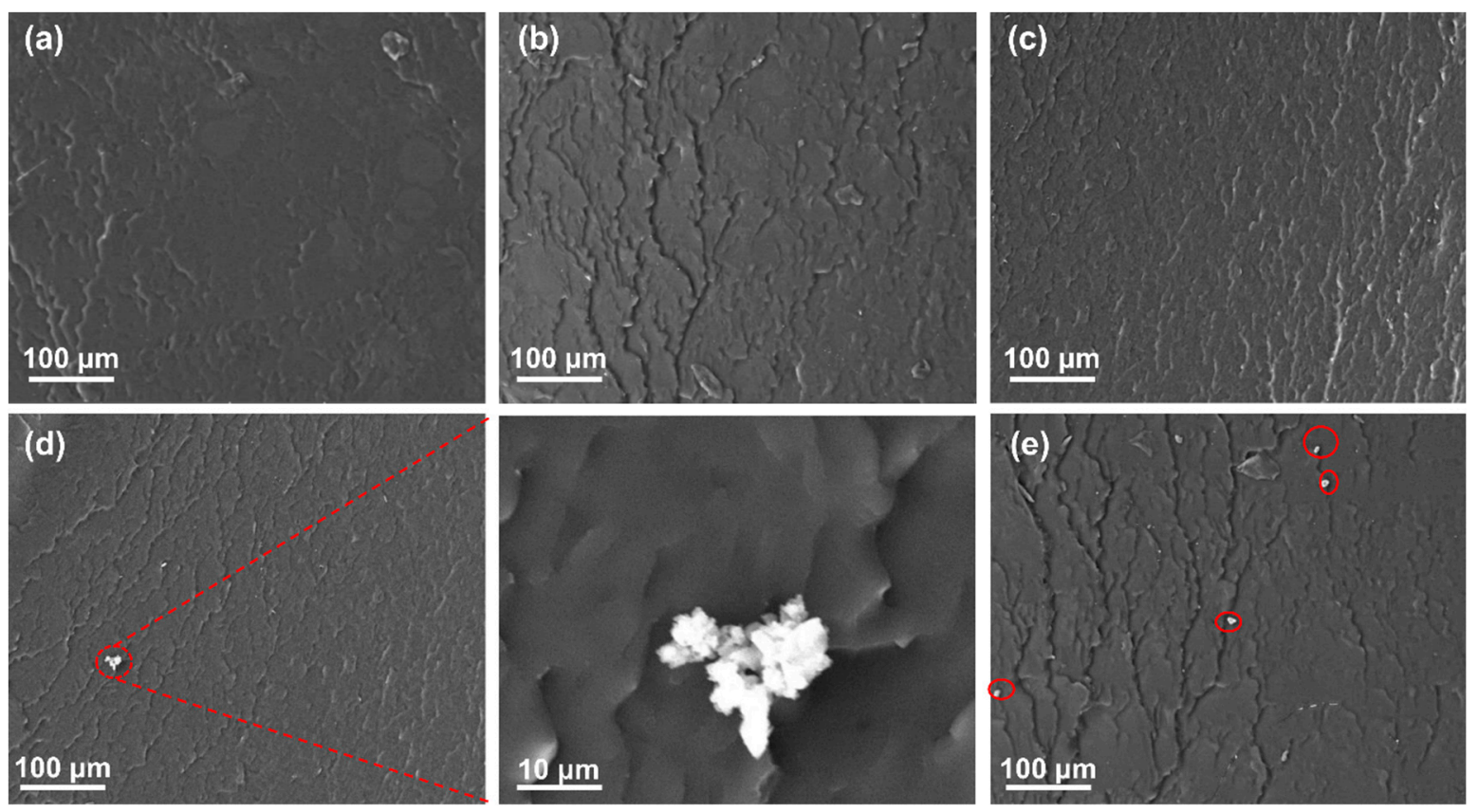

Figure 10. SEM micrographs of fractured nanocomposites filled with different weight parts nano-SiO 2 (a) 0 , (b) 1.0, (c) 1.5, (d) 2.0 and (e) 2.5 .

\section{Conclusions}

The activation energies obtained by Kissinger and Ozawa methods are 51.92 and $48.64 \mathrm{~kJ} / \mathrm{mol}$, respectively. The experimental dependence of $E_{\alpha}$ on $\alpha$ determined from the model-free isoconversional kinetics analysis method of Ozawa-Flynn-Wall can be adequately interpreted in terms of the autocatalytic curing reaction mechanisms of the phenolic amine/epoxy resin system.

The effects of the nano- $\mathrm{SiO}_{2}$ particles content on the tensile properties and fracture surface morphology of nanocomposites were also investigated. Studies of the morphology of fracture faces suggest that a uniform distribution of $\mathrm{SiO}_{2}$ nanoparticles is essential in promoting tensile properties. The tensile performance of nanocomposites reached its optimum at 1.5 weight parts of $\mathrm{SiO}_{2}$ nanoparticle addition, where $184.1 \%$ and $217.2 \%$ increases were achieved for tensile strength and tensile modulus compared to the pure epoxy resin, respectively.

Author Contributions: Conceptualization, X.W. and Y.Q.; methodology, X.W. and C.B.; formal analysis, T.Z. and Y.C.; investigation, C.L. and Y.J.; data curation, C.L. and Y.J.; writing-original draft preparation, X.W., T.Z. and C.L; writing-review and editing, X.W.; supervision, X.W., X.Z. and Y.Q.; project administration, X.W. and Y.Q.; funding acquisition, X.W. and Y.Q.

Funding: This research was funded by the "7th Generation Ultra Deep Water Drilling unit Innovation Project".

Conflicts of Interest: The authors declare no conflict of interest.

\section{References}

1. Rui, Z.; Han, G.; Zhang, H.; Wang, S.; Pu, H.; Ling, K. A new model to evaluate two leak points in a gas pipeline. J. Nat. Gas Sci. Eng. 2017, 46, 491-497. [CrossRef]

2. Jasper, A. Oil/Gas Pipeline Leak Inspection and Repair in Underwater Poor Visibility Conditions: Challenges and Perspectives. J. Environ. Prot. 2012, 3, 394-399. [CrossRef]

3. Murvay, P.S.; Silea, I. A survey on gas leak detection and localization techniques. J. Loss Prev. Process Ind. 2012, 25, 966-973. [CrossRef]

4. Sen, R. Advances in the application of FRP for repairing corrosion damage. Prog. Struct. Eng. Mater. 2003, 5, 99-113. [CrossRef]

5. Sen, R.; Mullins, G. Application of FRP composites for underwater piles repair. Compos. Part B 2007, 38, 751-758. [CrossRef] 
6. Wang, F.; Fang, H.; Li, B.; Cui, C.; Wang, Y. The mechanical behaviour of drainage pipeline under traffic load before and after polymer grouting trenchless repairing. Tunn. Undergr. Sp. Technol. 2018, 74, 185-194.

7. Mihai, M. Curing behavior, thermal, and mechanical properties of epoxy resins cured with a novel liquid crystalline dicarboxylic acid curing agent. Polym. Eng. Sci. 2014, 54, 695-703.

8. Zheng, Y.; Ning, R.; Zheng, Y. Study of $\mathrm{SiO}_{2}$ nanoparticles on the improved performance of epoxy and fiber composites. J. Reinf. Plast. Compos. 2005, 24, 223-233. [CrossRef]

9. Rajadurai, A. Thermo-mechanical characterization of siliconized E-glass fiber/hematite particles reinforced epoxy resin hybrid composite. Appl. Surf. Sci. 2016, 384, 99-106.

10. Liu, H.; Xu, K.; Ai, H.; Zhang, L.; Chen, M. Preparation and characterization of phosphorus-containing Mannich-type bases as curing agents for epoxy resin. Polym. Advan. Technol. 2009, 20, 753-758. [CrossRef]

11. Atta, A.M.; Shaker, N.O.; Maysour, N.E. Influence of the molecular structure on the chemical resistivity and thermal stability of cured Schiff base epoxy resins. Prog. Org. Coatings 2006, 56, 100-110. [CrossRef]

12. Cai, H.; Li, P.; Sui, G.; Yu, Y.; Li, G.; Yang, X.; Ryu, S. Curing kinetics study of epoxy resin/flexible amine toughness systems by dynamic and isothermal DSC. Thermochim. Acta 2008, 473, 101-105. [CrossRef]

13. Taylor, A.C.; Carolan, D.; Ivankovic, A.; Kinloch, A.J.; Sprenger, S. Toughening of epoxy-based hybrid nanocomposites. Polymer 2016, 97, 179-190.

14. He, H.; Li, K.; Wang, J.; Sun, G.; Li, Y.; Wang, J. Study on thermal and mechanical properties of nano-calcium carbonate/epoxy composites. Mater. Des. 2011, 32, 4521-4527. [CrossRef]

15. Boumaza, M.; Khan, R.; Zahrani, S. An experimental investigation of the effects of nanoparticles on the mechanical properties of epoxy coating. Thin Solid Films 2016, 620, 160-164. [CrossRef]

16. Purohit, P.J.; Huacuja-Sánchez, J.E.; Wang, D.Y.; Emmerling, F.; Thünemann, A.; Heinrich, G.; Schönhals, A. Structure-property relationships of nanocomposites based on polypropylene and layered double hydroxides. Macromolecules 2011, 44, 4342-4354. [CrossRef]

17. Gu, H.; Ma, C.; Gu, J.; Guo, J.; Yan, X.; Huang, J.; Zhang, Q.; Guo, Z. An overview of multifunctional epoxy nanocomposites. J. Mater. Chem. C 2016, 4, 5890-5906. [CrossRef]

18. Yuming, H.; Liang, Y. Curing Agent; Chemical Industry Press: Beijing, China, 2004; pp. 22-23.

19. Hu, J.; Hao, W.; Xing, L.; Zhang, J.; Yang, W.; Chen, L. Isoconversional analysis of non-isothermal curing process of epoxy resin/epoxide polyhedral oligomeric silsesquioxane composites. Polym. Test. 2011, 30, 349-355.

20. Lakho, D.A.; Yao, D.; Cho, K.; Ishaq, M.; Wang, Y. Study of the Curing Kinetics toward Development of Fast-Curing Epoxy Resins. Polym.-Plast. Technol. Eng. 2017, 56, 161-170. [CrossRef]

21. He, Y. DSC and DEA studies of underfill curing kinetics. Thermochim. Acta 2001, 367-368, 101-106. [CrossRef]

22. Kissinger, H.E. Reaction Kinetics in Differential Thermal Analysis. Anal. Chem. 1957, 29, $1702-1706$. [CrossRef]

23. Ozawa, T. Kinetic analysis of derivative curves in thermal analysis. J. Therm. Anal. 1970, 2, 301-324. [CrossRef]

24. Safarpour, M.A.; Omrani, A.; Afsar, S.; Zare-Hossein-Abadi, D. Study of cure kinetics of epoxy/DDS/nanosized $\left(\mathrm{SiO}_{2} / \mathrm{TiO}_{2}\right)$ system by dynamic differential scanning calorimetry. Polym. Adv. Technol. 2011, 22, 718-723. [CrossRef]

25. Crane, L.W.; Dynes, P.J.; Kaelble, D.H. Curing kinetics in polymer composites. J. Polym. Sci. Part C 1974, 12, 473-475.

26. Ren, R.; Chen, P.; Lu, S.; Xiong, X.; Liu, S. The curing kinetics and thermal properties of epoxy resins cured by aromatic diamine with hetero-cyclic side chain structure. Thermochim. Acta 2014, 595, 22-27.

27. Rivero, G.; Pettarin, V.; Vázquez, A.; Manfredi, L.B. Curing kinetics of a furan resin and its nanocomposites. Thermochim. Acta 2011, 516, 79-87. [CrossRef]

28. Omrani, A.; Ghaemy, M.; Rostami, A.A. Thermosetting polymers from epoxy resin and a Nickel catalyst of diethylenetriamine. J. Therm. Anal. Calorim. 2009, 98, 477-483. [CrossRef]

29. Flynn, J.H.; Wall, L.A. A quick, direct method for the determination of activation energy from thermogravimetric data. J. Polym. Sci. Part B Polym. Lett. 1966, 4, 323-328. [CrossRef]

30. Zhang, J.-J.; Ren, N. A new kinetic method of processing TA data. Chinese J. Chem. 2010, 22, 1459-1462. [CrossRef]

31. Vyazovkin, S.; Sbirrazzuoli, N. Mechanism and kinetics of epoxy-amine cure studied by differential scanning calorimetry. Macromolecules 1996, 29, 1867-1873. [CrossRef] 
32. Liu, F.; Wang, Z.; Liu, D.; Li, J. Curing of diglycidyl ether of bisphenol-A epoxy resin using a poly(aryl ether ketone) bearing pendant carboxyl groups as macromolecular curing agent. Polym. Int. 2009, 58, 912-918. [CrossRef]

33. Vyazovkin, S. Isoconversional Kinetics of Thermally Stimulated Processes; Springer International Publishing: New York, NY, USA, 2015; ISBN 9783319141749.

34. Ferdosian, F.; Ebrahimi, M.; Jannesari, A. Curing kinetics of solid epoxy/DDM/nanoclay: Isoconversional modelsversus fitting model. Thermochim. Acta 2013, 568, 67-73. [CrossRef]

35. Perrin, F.X.; Nguyen, T.M.H.; Vernet, J.L. Kinetic analysis of isothermal and nonisothermal epoxy-amine cures by model-free isoconversional methods. Macromol. Chem. Phys. 2007, 208, 718-729. [CrossRef]

36. Zare, Y.; Rhee, K.Y.; Hui, D. Influences of nanoparticles aggregation/agglomeration on the interfacial/ interphase and tensile properties of nanocomposites. Compos. Part B 2017, 122, 41-46. [CrossRef]

37. Rahman, I.A.; Padavettan, V. Synthesis of Silica Nanoparticles by Sol-Gel: Size-Dependent Properties, Surface Modification, and Applications in Silica-Polymer Nanocomposites-A Review. J. Nanomater. 2012, $2012,8$. [CrossRef]

38. Zamanian, M.; Mortezaei, M.; Salehnia, B.; Jam, J.E. Fracture toughness of epoxy polymer modified with nanosilica particles: Particle size effect. Eng. Fract. Mech. 2013, 97, 193-206. [CrossRef]

39. Jiang, Y.; Tohgo, K.; Shimamura, Y. Ultrasonic dispersion of $\mathrm{SiO}_{2}$ particles in glassy epoxy resin. J. Compos. Mater. 2012, 46, 1159-1168. [CrossRef]

(C) 2019 by the authors. Licensee MDPI, Basel, Switzerland. This article is an open access article distributed under the terms and conditions of the Creative Commons Attribution (CC BY) license (http://creativecommons.org/licenses/by/4.0/). 